\title{
Bilateral facial weakness following dengue fever
}

\author{
Samir Patel ${ }^{1}$, Rajeev Ranjan ${ }^{1}$, Ritu Verma² ${ }^{2}$ C. S. Agrawal ${ }^{1}$, Pooja Gupta ${ }^{1}$ \\ ${ }^{1}$ Department of Neurology, Sir Ganga Ram Hospital, New Delhi 110060, India. \\ ${ }^{2}$ Department of Nuclear Medicine, Sir Ganga Ram Hospital, New Delhi 110060, India.
}

\section{A B S T R A C I}

Dengue, an acute viral disease transmitted by Aedes mosquitoes, is highly endemic in many tropical and subtropical areas of the world. Dengue has a wide clinical spectrum, ranging from mild clinical febrile illness to severe life-threatening conditions like dengue hemorrhagic fever and dengue shock syndrome. Neurological complications of dengue infection have been observed more frequently in the recent past. They are widespread and may involve almost all parts of nervous system through various pathogenic mechanisms. We report a case of a 30-year old male who developed bilateral facial weakness after dengue fever.

Key words: Bilateral facial weakness; dengue fever

\section{INTRODUCTION}

Dengue is second most common mosquito-borne disease affecting humans after malaria. ${ }^{[1]}$ Around 2.5 billion population is at risk of dengue infection worldwide, and its endemic zone comprises more than 100 countries of the world. It is caused by arbo viruses which belong to the Flaviviridae family. Dengue virus 1-4 are the known serotypes of the virus. ${ }^{[1]}$ The clinical presentation of dengue has a wide spectrum, ranging from mild clinical febrile illness to severe lifethreatening conditions like dengue hemorrhagic fever and dengue shock syndrome. Recently, virological characteristics of dengue viruses have been changing, resulting in widespread neurological complications. ${ }^{\left[{ }^{[2]}\right.}$

Neurological manifestations of dengue infection can be grouped into 3 categories: (1) concerned with neurotropism leading to encephalitis, meningitis, myositis, rhabdomyolysis and myelitis; (2) related to the systemic complications of dengue infection that can lead to encephalopathy, stroke (both hemorrhagic and ischemic), hypokalemic paralysis and papilledema; (3) post-infectious leading to acute disseminated encephalomyelitis, encephalomyelitis, myelitis, neuromyelitis optica, optic neuritis, Guillain-Barré

Corresponding Author: Dr. Samir Patel, Department of Neurology, Sir Ganga Ram Hospital, Old Rajinder Nagar, New Delhi 110060, India. E-mail: samirpatel343@yahoo.com

\begin{tabular}{|l|l|}
\hline \multicolumn{2}{|c|}{ Access this article online } \\
\hline Quick Response Code: & Website: \\
\hline & www.nnjournal.net \\
\cline { 2 - 2 } & DOI: 10.20517/2347-8659.2015.48 \\
\hline
\end{tabular}

syndrome probable Miller-Fisher syndrome, phrenic neuropathy, long thoracic neuropathy, oculomotor palsy, maculopathy and fatigue syndrome. ${ }^{[3]}$ We report a case of a 30-year old male, who developed bilateral facial weakness after dengue fever.

\section{CASE REPORT}

A 30-year-old male, without any significant past medical illness presented with difficulty in talking followed by difficulty in eating and drinking. His wife also noticed that he was unable to close his eyes. There was no history of any limb weakness or paraesthesia. He also had fever for two weeks that lasted for 3-4 days. On presentation, he was conscious, alert and followed verbal commands. He was hemodynamically stable and his physical examination was unremarkable. However, following a neurologic examination, a bifacial lower motor neuron weakness was marked. His motor and sensory examination was unremarkable.

MRI scan of his brain with contrast study was concluded as normal. Electrophysiological evaluation of facial nerve revealed normal latency and reduced amplitude. His peripheral nerve conduction study was normal. He was also evaluated for fever and found

This is an open access article distributed under the terms of the Creative Commons Attribution-NonCommercial-ShareAlike 3.0 License, which allows others to remix, tweak, and build upon the worknon-commercially, as long as the author is credited and the new creations are licensed under the identical terms.

For reprints contact: service@oaepublish.com

Cite this article as: Patel S, Ranjan R, Verma R, Agrawal CS, Gupta P. Bilateral facial weakness following dengue fever. Neuroimmunol Neuroinflammation 2016;3:63-4.

Received: 03-11-2015; Accepted: 18-12-2015 
to have dengue IgM antibody positive. Vasculitic markers, serum ACE and lyme serology were negative. He underwent CSF evaluation which revealed cytoalbuminologic dissociation. (Cell count: 10, 100\% lymphocytes, Protein: 100, Sugar: 77, PCR for CMV: Negative, PCR for Herpes: Negative). He was managed with low dose steroid and physiotherapy. His facial weakness improved gradually and was discharged.

\section{DISCUSSION}

Dengue has been a known clinical entity since $1780 .^{[4]}$ The association of dengue infection and neurological abnormalities was first described by Sanguansermsri and colleagues in 1976, in a patient presenting with encephalopathy. ${ }^{[5]}$ Many neurological symptoms are associated with dengue and have been recognized for over a century. The classic signs of acute infection are headache, dizziness, lightheadedness, insomnia, agitation, irritability and depression. A minority of symptoms manifests as encephalopathy. ${ }^{[6]}$

Among the neurological manifestations that appear post-dengue, meningoencephalomyelitis, transverse myelitis, post-infectious encephalitis, epilepsy, tremors, Bell's palsy, mononeuropathy and Guillain-Barré syndrome (GBS) stand out. ${ }^{[7]}$ GBS is a rare complication of dengue fever with an incidence of between 0.6 and 1.9 per $100,000 .^{[8]}$ The pathophysiology of these neurological complications can be explained by the occurrence of cerebral edema, cerebral hemorrhage, cerebral anoxia, hyponatremia, liver failure associated with portal-systemic encephalopathy, micro-capillary hemorrhage or release of toxic products. ${ }^{[9]}$

Bilateral facial weakness may be a component of GBS. However, isolated bifacial weakness has not been reported to our knowledge. Although CSF albumino- cytological dissociation was present in our case, but electrophysiological evaluation and neurological evaluation was normal except bilateral lower motor neuron type facial weakness. Our case calls for special attention because the dengue infection remains a serious public health problem in tropical countries such as India, but little is known about the actual incidence of neurological complication of dengue.

\section{Financial support and sponsorship}

Nil.

\section{Conflicts of interest}

There are no conflicts of interest.

\section{REFERENCES}

1. WHO. Dengue guidelines for diagnosis, treatment, prevention and control. Geneva: World Health Organization; 2009.

2. Verma R, Sharma P, Garg RK, Atam V, Singh MK, Mehrotra HS. Neurological complications of dengue fever: Experience from a tertiary center of north India. Ann Indian Acad Neurol 2011;14:272-8.

3. Murthy JM. Neurological complication of dengue infection. Neurol India 2010;58:581-4.

4. Rush B. An account of the bilious remitting fever, as it appeared in Philadelphia, in the summer and autumn of the year 1780. In Medical inquiries and observations, 1st edition. Philadelphia: Prichard and Hall. 1789;89-100.

5. Pancharoen C, Thisyakorn U. Neurological manifestations in dengue patients. Southeast Asian J Trop Med Public Health 2001;32:341-5.

6. Gubler D. The emergence of epidemic dengue fever and dengue hemorrhagic fever in the Americas: a case of failed public health policy. Rev Panam Salud Publica 2005;17:221-4.

7. Puccioni-Sohler M, Soares CN, Papaiz-Alvarenga R, Castro MJ, Faria LC, Peralta JM. Neurologic dengue manifestations associated with intrathecal specific immune response. Neurology 2009;73:1413-7.

8. Goncalves E. Acute inflammatory demyelinating polyradiculoneuropathy (Guillain-Barre syndrome) following dengue fever. Rev Inst Med Trop Sao Paulo 2011;53:223-5.

9. Soares CN, Cabral-Castro MJ, Peralta JM, de Freitas MR, Zalis $\mathrm{M}$, Puccioni-Sohler M. Review of the etiologies of viral meningitis and encephalitis in a dengue endemic region. $J$ Neurol $S c i$ 2011;303:75-9. 